\title{
Tradição e modernidade no traje da baiana de escola de samba
}

VÂNIA MARIA MOURÃO ARAÚJO

LUIZ FELIPE FERREIRA

\section{Resumo}

O artigo traz reflexões sobre os processos envolvidos na construção da chamada "baiana de escola de samba" compreendida como produto de negociações constantes de significado, reconhecendo nos elementos que constituem seu figurino, o jogo de influências que vão dialogar com a pluralidade e diversidade das convenções culturais.

Palavras-chave:

Carnaval carioca, baiana, escola de samba 


\title{
Tradition and modernity in the samba school "baiana" costume
}

\author{
VÂNIA MARIA MOURÃO ARAÚJO \\ LUIZ FELIPE FERREIRA
}

\section{Abstract}

In this article, we will reflect on the influences and processes involved in construction, development and establishment of the "Bahian samba school" Carnival in Rio, as the product of constant negotiation of meaning, by recognizing the visual signs made on their wardrobe, set of influences ranging dialogue with the plurality and diversity of cultural conventions, and considering the story of a carnival produced by a series of tensions manifested in its urban samba-school space as a reflection on the ongoing construction of these representations and reframes. 


\section{Introdução}

A figura da baiana, definida frequentemente como um tipo regional feminino brasileiro, se organiza a partir de uma ideia concebida e produzida a partir do século XIX, cujo processo de construção estabeleceu diferentes formas de representação e significação ao longo de um percurso onde a indumentária foi fundamental.

As representações, em desenhos, aquarelas e pinturas, feitas por artista viajantes - como Carlos Julião, Joaquim Cândido Guillobel, Henry Chamberlain, Debret e Rugendas entre outros - de aspectos pitorescos da vida cotidiana da cidade do Rio de Janeiro (Figura 1) colaboraram para a criação de uma tipologia popular ao definir diversos personagens-tipos que iriam caracterizar os habitantes das terras brasileiras. Entre estes, destacavam-se as negras vendedoras representadas em suas atividades diárias.

Já em finais do século XIX, no Rio de Janeiro, algumas mulheres negras, conhecidas como "tias baianas", se tornariam figuras centrais no processo de valorização e organização das camadas populares, assumindo papéis relevantes na sociedade ao reunir em suas casas representantes da elite e da população mais carente em torno de manifestações em que o traço negro era elemento preponderante, como as rodas de samba e os candomblés (VELLOSO, 1990; MOURA, 2004).

Nas primeiras décadas do século XX, o aumento do interesse mundial pela cultura negra, conhecido como negrofilia (ARCHER-STRAW, 200o) iria mobilizar a Europa e os Estados Unidos, influenciando, por conseguinte, a intelectualidade brasileira que passa a valorizar a cultura dos morros cariocas e sua ligação com as raízes africanas (FERREIRA, 2004).

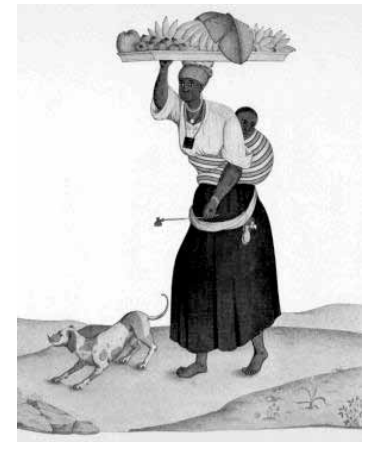

Figura 1

Negras vendedoras. Carlos Julião, último quarto do século 18. (JULIÃO, 196o, Prancha XXXIII) 


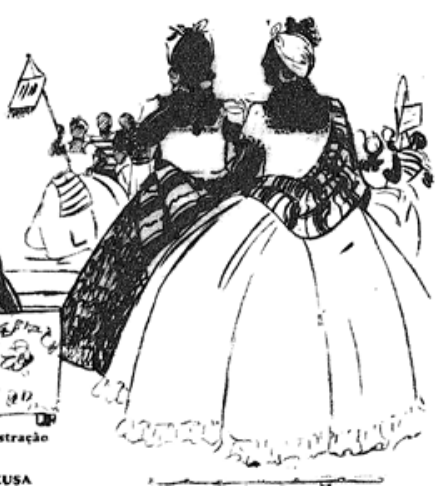

Figura 2 Ilustração assinada por Creusa representando uma cena de carnaval de rua. Em primeiro plano estão duas baianas ao lado de um carrinho de vendas, provavelmente de limonadas, costume bastante comum na Praça Onze e bem comentado nos jornais da época (Gazeta de Notícias, 2 de março de 1935, p. 1).

Figura 3

"legítima baiana, de hábitos conservadores, e, geralmente, doceira". (MEIRELLES, 2003, p.26)

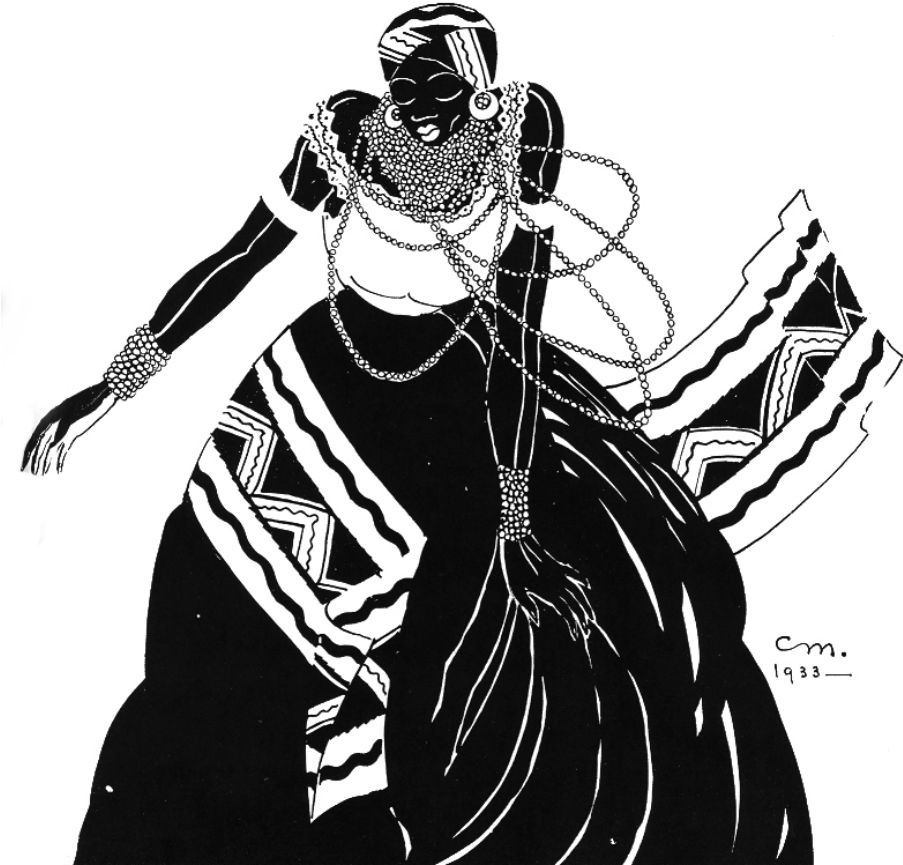

A imagem da baiana se estabeleceria a partir daí como um dos símbolos da cultura popular brasileira e de sua manifestação mais essencial, o carnaval "nascido do povo", representado pela nova forma de organização carnavalesca: as escolas de samba (figura 2).

Neste contexto, a vestimenta das baianas é de grande importância para a fixação de sua imagem. O traje "típico" da baiana quituteira que conhecemos hoje (composto de elementos visuais marcantes como a saia rodada, o turbante, o pano-da-costa, as batas rendadas e os balangandãs, entre outros) refere-se às vestimentas das "baianas vendedoras de acarajé" e "baianas de tabuleiros" cheios de quitutes encontrados nas ruas das principais cidades brasileiras no século XIX, com destaque para o Rio de Janeiro.

Um momento importante do processo de valorização (e organização formal) deste imaginário é a inauguração na Pró-Arte, no Rio de Janeiro, em 1933, de uma importante exposição que obteve grande repercussão na época. Intitulada "Batuque, samba e macumba", a mostra de desenhos e textos de Cecília Meirelles tinha como tema o folclore negro no Brasil e seu eixo na figura da "legítima baiana" (figura 3) e sua 
indumentária característica (MEIRELLES, 2003). O olhar da artista e pesquisadora ajudou a fixar a forma da "baiana carioca”, ligada ao samba e ao carnaval através dos blocos, ranchos e cordões que representavam a festa popular da cidade na virada para o século XX. Ao definir e tipificar, com suas ilustrações e descrições, as diferentes "categorias" de baianas (a baiana popular, a baiana de macumba e a baiana carnavalizada), Cecília Meirelles fixaria os elementos visuais que, pouco tempo depois, serviriam para definir as baianas de escolas de samba (FERREIRA, 2004).

A partir dos anos de 40, com o sucesso da canção "O que é que a baiana tem?" de Dorival Caymmi e a projeção internacional da cantora Carmem Miranda, novos significados são acrescentados a esse traje tão emblemático. Desde então, a baiana será um personagem carnavalesco definitivamente reconhecido, um ícone internacional "genuinamente" brasileiro (Figura 4) construído sobre diversas camadas de significados.

\section{A baiana de escola de samba: espaço da tradição}

A presença de grupos de baianas já nas primeiras aparições de escolas de samba na virada dos anos 20 para os anos 30 é conseqüência da importância adquirida por essa personagem ao incorporar elementos visuais e significados acumulados nos cem anos anteriores. Significados estes que teriam papel importante na definição da característica popular e da autenticidade destes grupos carnavalescos legitimando, assim, a ideia de um carnaval puro, com autênticas raízes na cultura popular brasileira desejado e negociado pelas escolas e pela sociedade (TURANO, 2012). (Figura 5) Consideradas, já nos seus primeiros anos, como um dos elementos "tradicionais" das escolas, as baianas vêm continuamente incorporando novos significados a sua figura e adquirindo novas funções nos desfiles, transitando entre o lúdico e o sagrado, num espaço de constante tensão entre tradição e modernidade.

A partir da década de 1930 e durante todo o resto do século $\mathrm{XX}$ as baianas se manterão nos desfiles das escolas de samba como elementos importantes para se entender as tensões entre tradição e modernidade, expressando, em sua vestimenta a complexidade deste diálogo.

O período que vai dos anos 30 aos 50 pode ser considerado como aquele de constituição das escolas de samba, quan-

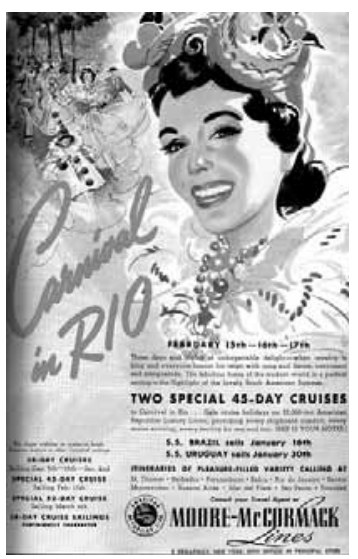

Figura 4

Cartaz de uma empresa de aviação, anunciando o Carnaval no Rio de Janeiro no ano de 1945 , utilizando a imagem emblemática da baiana.

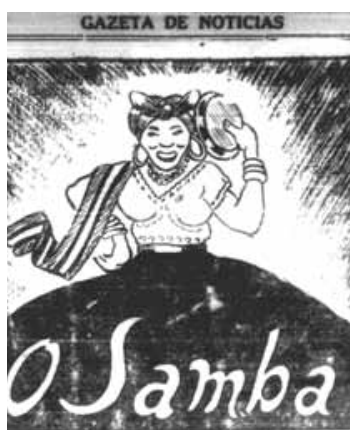

Figura 5

Ilustração de um tipo de baiana popular e tradicional, trazendo como adereço de mão não mais o tabuleiro, mas um pandeiro, personificando um ritmo considerado essencialmente brasileiro: o samba (Gazeta de Notícias, 03 de março de 1946, p. 11). 
do estas se organizam estruturalmente e se impõem como a mais legítima manifestação cultural carnavalesca, no lugar dos ranchos, cordões e blocos. Neste período o traje da baiana dialoga com a visualidade da baiana popular e tradicional, representada por uma estética que definimos como "folclórica". A indumentária mantém estrutura vestimentar relacionada à das negras escravas, das baianas crioulas e das tias baianas, destacando alguns elementos determinantes como a saia rodada, o turbante, o pano da costa, os balangandãs e a bata. Tais elementos lhe conferem "corpo", identidade visual e "essência", característicos, que fundamentam e estruturam não somente um carnaval que louva a tradição e que se apropria da memória coletiva da cultura popular brasileira, mas também uma escola de samba que assume a função de espaço folclórico, preocupada em emprestar aos festejos o caráter brasileiro. Segundo Ferreira (2004) as escolas de samba seriam, nesse momento, reconhecidas e exaltadas principalmente pela música do samba valorizado como ritmo nacional, incorporando uma espécie de brasilidade essencial e expressando a "alma" profunda do povo. Faria (2009), por sua vez, ressalta o papel das escolas de samba durante o período do Estado Novo ao louvar, cantar e contar em seus enredos a história do Brasil, construindo pela via carnavalesca, a ideia de um país abençoado por Deus.

É importante destacar, entretanto, que embora a baiana de carnaval tenha se tornado um tipo público durante a primeira metade do século XX, essa autoridade e prestígio não resultaram em grande interesse por parte da imprensa carioca até o final dos anos 50. Na verdade, entre as décadas 1930 a 1950 os periódicos da cidade reservaram espaço muito reduzido para as baianas e para o carnaval das escolas de samba de modo geral, principalmente no que se refere à iconografia.

As notícias sobre a presença de "conjuntos" de baianas nos desfiles de escolas de samba em jornais cariocas destacam a valorização do caráter nacionalista e popular destas agremiações carnavalescas manifestado na cor das fantasias e nos elementos portados sobre as cabeças ou nas mãos, conforme exemplos a seguir, retirados de diversos jornais:

A escola de samba "Depois eu digo". Sede, Salgueiro. Enredo: "Uma Manhã no Salgueiro". O enredo dessa Escola de Samba está assim redigido: $1^{\underline{a}}$ parte: Comissão de frente, composta da Diretoria da escola, trajando terno branco e gravata verde. Original abre-alas confeccionado em um painel e iluminado com a linda paisagem do Morro do Salgueiro [...] Entra em 
seguida o corpo coral organizado em duas alas, composto de um grupo de pastoras, fantasiadas de baianas, ninando pequenos bebês. Ambos fantasiados com cores verde e branco, que são precisamente as cores de nossa bandeira. (JORNAL DO BRASIL, o3 de março de 1935, p. 10)

O enredo da Escola de Samba Azul e Branco foi extraído da vida noturna da cidade. [...] $3^{\underline{a}}$ parte. COCK-TAIL - AZUL E BRANCO. Duas alas de Baianas nos seus trajes carcterísticos, trazendo sobre a cabeça um cock-tail para você. (JORNAL DO BRASIL, o4 de fevereiro de 1940)

Escola de samba "Fique-firme". Favela. Enredo: "Sonho de um pintor". Descrição do cortejo: [...] 2 2 $2^{\text {a }}$ tela: "Você já foi à Bahia?" Corpo coral feminino. Numeroso grupo de pastoras com as cores da nossa Escola com o traje característico de baianas com artísticos turbantes floridos na cabeça dão motivo a este quadro cada pastora conduzirá nas mãos uma linda paleta. (GAZETA DE NOTÍCIAS, 15 de fevereiro de 1942, p. 11)

Um dos melhores trabalhos apresentados ao desfile - senão o melhor - foi o dos "Aprendizes de Lucas" que, numa concepção de Marcilio de Marques, fizeram exaltação à Bahia. Um carro alegórico muito bem confeccionado mostrava o Elevador Lacerda e a Igreja do Senhor do Bonfim. [...] Baianas com pequenas igrejas na cabeça, com bonecos brancos simbolizando os esforços da mãe preta no tempo da escravidão. (O Globo, 20 de fevereiro de 1950, p. 10)

Escola de samba "Floresta do Andaraí" [...] esta cujo motivo era a "Primeira Missa do Brasil", apresentava muitas baianas, levando pequenas caravelas sobre a cabeça e cantando um sugestivo samba com alusões ao tema do desfile. (O Globo, 18 de fevereiro de 1953, p. 10)

\section{A baiana de escola de samba e o carnaval espetáculo}

No inicio dos anos 1960, as baianas passariam por uma série de transformações marcantes em seu aspecto visual. Nesse momento, o tema da visualidade ganha predomínio nas escolas de samba, provocando grande mudança na estética dos desfiles como já sugeria a manchete do jornal "O Globo" de 15 de fevereiro de 1956 - "Ritmo, beleza e luxo no espetáculo" 
- evidenciando a riqueza e o "conjunto de policrômica beleza" dos trajes das "baianas", apresentados nos desfiles daquele ano pelas escolas de samba (p. 10).

Para Ferreira (2004), estas modificações seriam consequência da interferência da intelectualidade nas manifestações populares, buscando "preservá-las" do avanço da indústria cultural, vista, então como sinônimo de americanização e, portanto, capaz de contaminar a "pureza" das escolas de samba. A participação direta destes elementos, vindos das classes mais favorecidas seria a ponta de lança daquilo que se convencionou chamar de "invasão da classe média", mas que pode ser mais bem entendido como uma nova relação da sociedade com o popular que, no caso das escolas de samba, passa a ser visto como um espaço de participação inicialmente política e logo depois social. Uma das consequências desta mudança de paradigma seria o grande interesse que a elite e a classe média passariam a ter pelos desfiles e ensaios de algumas escolas de samba (quase sempre aquela consideradas mais tradicionais) como se pode ver nas notícias abaixo:

O terreiro da "Estação Primeira de Mangueira" transformou-se na noite de quinta-feira passada, quando teve lugar o ensaio geral da famosa "escola", em um ambiente de alta sociedade. Cerca de centenas de carros da Zona Sul se dirigiram ao famoso morro, transportando pessoas de destaque do "Café Society" carioca, membros do corpo diplomático e "lindos" brotinhos de Copacabana e Arpoador. (O Globo, 19 de fevereiro de 1955, p. 9)

O desfile das Escolas de Samba está atraindo gente da chamada "Coté Society". Como o flagrante mostra, o casal Ermelindo Matarazzo e amigos estiveram no palanque da Avenida aplaudindo o "Império Serrano" e outras escolas de samba. (O Globo, 23 de fevereiro de 1955, p. 10)

A escola de samba Acadêmicos do Salgueiro estabeleceria um marco para este momento, ao aceitar o oferecimento do intelectual Fernando Pamplona (cenógrafo e professor da Escola de Belas Artes) para chefiar sua equipe de criação que incluía inicialmente o folclorista Dirceu Nery a artista plástica e figurinista Marie-Louise Nery e, logo depois, o figurinista Arlindo Rodrigues, entre outros, o que "iria desencadear uma verdadeira revolução na temática e no tratamento plástico das escolas de samba" (FERREIRA, 1999, p. 81). 


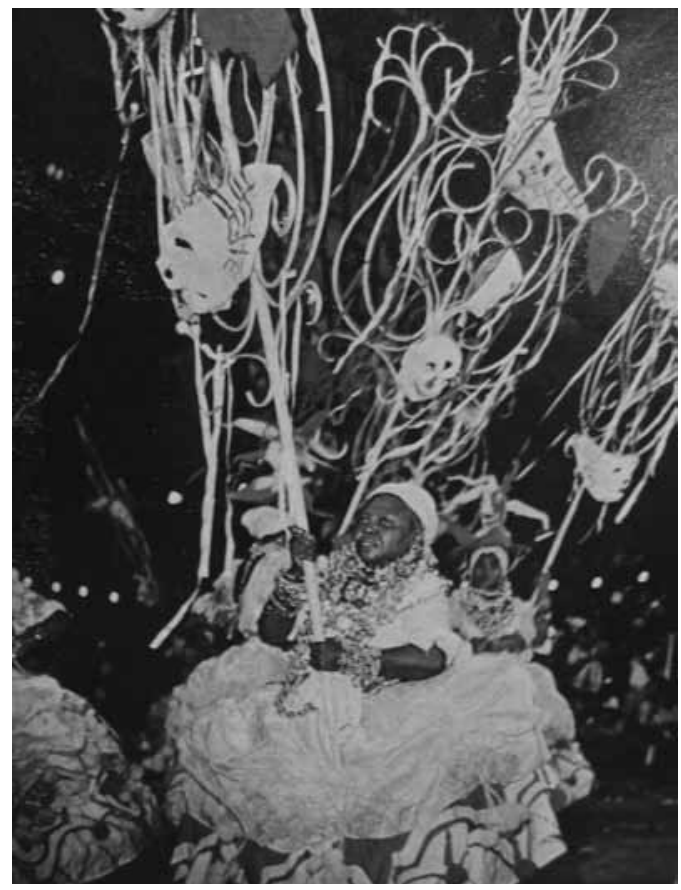

Ao trazer para seus quadros, profissionais de outras áreas - como as artes visuais, teatro, televisão e cinema, por exemplo - e intelectuais universitários com valores estéticos diferenciados, as escolas de samba estabeleceriam novos conflitos e disputas nos quais a incorporação de elementos externos dialogaria com as tradições, estabelecendo novos paradigmas para a visualidade das escolas e das baianas.

Podemos observar nesse período que, embora guardasse memórias da visualidade "folclórica", a baiana tornava-se mais "espetacular". À sua indumentária típica e "tradicional" seriam acrescentados adereços que as integravam de forma consistente á história narrada pelo enredo. (FERREIRA, 1999, p. 85) (figura 6)

O fato é que se consolidava, na nova organização e hierarquia das escolas de samba liderada pela autoridade do carnavalesco, profissional que pesquisava e definia o enredo, concebia as alegorias, criava os figurinos, desenhava as fantasias, indicava os materiais e as cores que deveriam ser usadas e acompanhava o processo de desenvolvimento e montagem desses projetos.

Na chegada dos anos de 1970, algumas escolas de samba, como a Mangueira e a Portela, haviam-se fixado no imaginário do povo como guardiãs da autêntica cultura popular
Figura 6

Baianas com alegorias de mão, elemento inovador no que se refere às estas personagens, representando uma "evocação das vendedoras de máscaras do velho carnaval". Acadêmicos do Salgueiro, 1965. Criação de Arlindo Rodrigues e Fernando Pamplona (MANCHETE, 20 de março de 1965, p.59). 
brasileira, mantendo a característica da pureza e incorporando a "aura" da tradição. Por outro lado, o discurso de luta e consciência política passou a ser uma característica marcante da organização de outras escolas como o Império Serrano ou o próprio Salgueiro (FERREIRA, 2009). Neste contexto, as escolas de samba deixam de ser um espaço folclórico, para se apresentar como um espaço político, de ação e como um espetáculo que precisa ser entendido a partir da organização e visualidade de suas alas. A ala das baianas torna-se um elemento essencial no sistema de representação dos enredos, assumindo um importante espaço de narrativa visual e incorporando novos significados e elementos como golas e esplendores.

Aos poucos, a ideia de padronização e de conjunto começa a se instalar, dentro da lógica de uniformização e organização das escolas. Mesmo aquelas mais "conservadoras" começam a rever seus valores estéticos, visando o novo público que se formara. $\mathrm{O}$ conjunto das baianas, que inicialmente desfilava de maneira espontânea e dispersa e com fantasias diferenciadas uma das outras passará, com a organização cada vez maior das alas, a desfilar de forma mais coesa, com fantasias similares nos mínimos detalhes, apresentando maior unidade visual, num processo que se desenrolará ao longo das décadas de 70/80.

Durante este período, as agremiações vão começar a movimentar elevados recursos para suas grandes produções incorporando e articulando novos interesses como os do Estado, do turismo e dos meios de comunicação. Algumas escolas iriam assumir claramente o discurso da espetacularidadede, como a Mocidade Independente de Padre Miguel, a Imperatriz Leopoldinense e a Beija-Flor. É também nesse momento que a baiana de escola de samba vai adquirir nova camada de significados, o de "grandes guerreiras do samba", representando "as cabeças coroadas pelos cabelos brancos, simbolizando a sabedoria africana dos mais velhos, [...] que dançavam o samba de roda da Bahia e louvavam os orixás" (THEODORO, 2009, p. 224).

Em 1982, o Império Serrano apresenta um enredo que marcaria uma espécie de crítica ao gigantismo das superescolas de samba, trazendo para a cena o tema da modernidade versus tradição, ou seja, a oposição entre o discurso da espetacularidade dos desfiles e aquele que valoriza a expressão da "autêntica cultura popular". Inserida nesse contexto está a baiana com sua indumentária traduzida por um sistema complexo de elementos visuais e códigos de identidade. 


\section{O que a baiana tem? Tem tradição? Tem! Tem modernidade? Tem! Tem pano da Costa? Nem sempre!}

Nas últimas três últimas décadas, a questão da visualidade será cada vez mais importante, o lucro será uma exigência e o tempo para o desfile será rigorosamente controlado. Uma nova organização passa a ser almejada, agora que as escolas precisam mostrar um espetáculo impecável que justifique ser vendido no país e no exterior. Esse período é definido pelo crescimento e expansão das agremiações e também das apresentações que ficarão cada vez mais elaboradas pondo-se a serviço, cada vez mais, dos aspectos visuais e narrativos do desfile.

Nessa fase em que as escolas de samba assumem seu poder empresarial e são reorganizadas sob a ação estratégica da Liga das Escolas de Samba, vai haver uma notável ampliação dos negócios, dos investimentos, da passarela de desfile e das fantasias das baianas que se expandem como se fizessem eco a tudo isto. As baianas tornam-se ainda mais essenciais ao sistema de representação dos enredos, passando a ter a importância de uma personagem e vindo a incorporar novos significados, representando noivas, estátuas da liberdade, seres espaciais, globo terrestre, poços de petróleo e até abelhas.

Ferreira (2004, p. 365) afirma que os carnavalescos "Rosa Magalhães, Max Lopes e Renato Lage estabeleceriam um novo padrão de qualidade estética para os desfiles, no qual os detalhes visuais e as novidades tecnológicas tornavam-se tão importantes quanto às 'tradições' do canto e da dança". É o caso da baiana com um tecido de estampa de onça concebida em 1987 pelo carnavalesco Fernando Pinto, ligado ao Tropicalismo, para a escola Mocidade Independente de Padre Miguel, ou da baiana com capacete espaciais no lugar do turbante criada pelo mesmo carnavalesco para a Mocidade no carnaval de 1985. (Figura 7)

As fantasias de baianas de escola de samba passavam a representar expressões da diversificação das formas e dos materiais, da experiência do carnavalesco, do enredo, das condições da escola e dos interesses do mercado (figura 8). A organização visual da escola, por sua vez, acaba expressando novos arranjos que serão impostos às alas. A marcha carnavalesca das escolas de samba vai alcançar uma ordenação precisa, minuciosa, trazendo para a ala de baianas, novos significados expressos na indumentária e na forma da apresentação da ala, cada vez mais organizada e coreografada. 

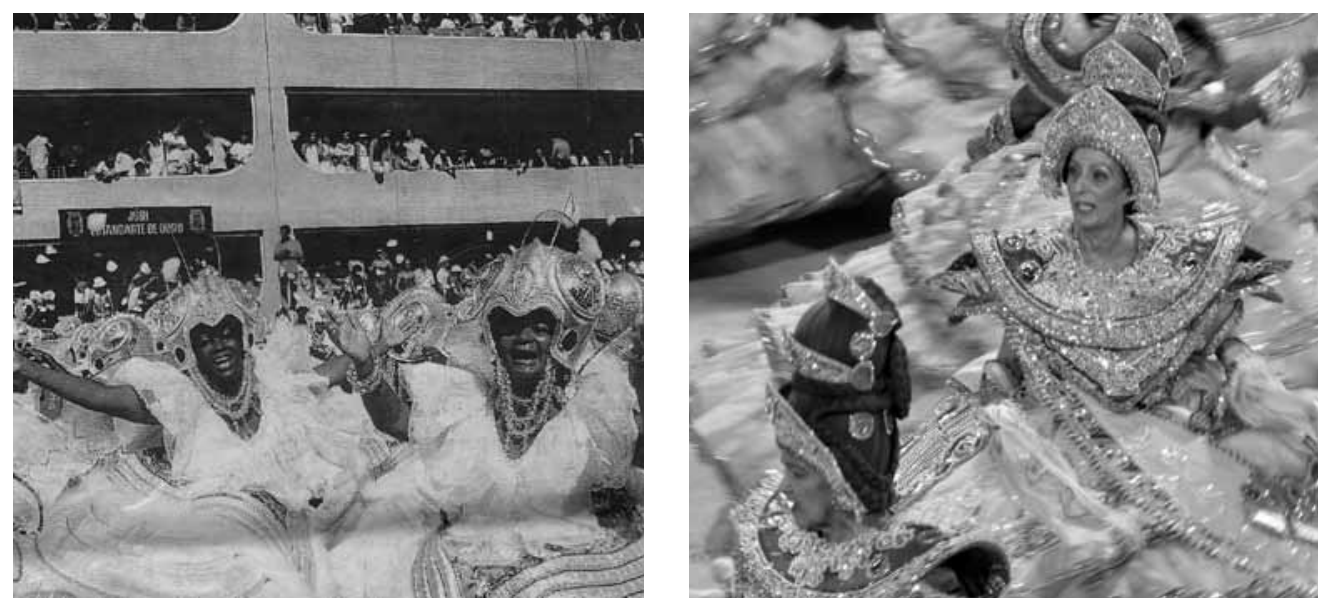

Figura 7

Ala de baianas com capacete espacial, da Mocidade Independente de Padre Miguel. Enredo Ziriguidum 2001, carnavalesco Fernando Pinto. Carnaval de 1985. (O Globo, 20 de fevereiro de 2011, p. 40)

Figura 8

Carnaval de 2011. Imperatriz Leopoldinense, Ala das baianas vencedora do troféu Estandarte de Ouro, com o enredo A Imperatriz adverte: sambar faz bem à saúde, de Max Lopes. (Foto Felipe Ferreira)
Por outro lado, a aceleração decorrente do controle do tempo de desfile impõe a necessidade de uma rápida decodificação das fantasias que precisam ter seus elementos facilmente decodificadas pela plateia. Nesse sentido, o conjunto da ala de baianas passa a representar grandes massas de cor e, algumas vezes, as componentes, juntas, vão possuir um único significado genérico, como por exemplo "as geleiras", "os redemoinhos", "as folhas secas", "a beleza dos mares" ou "os banhos e as porções para relaxar".

Numa perspectiva morfológica, a fantasia da baiana de hoje tem como marca estrutural uma ampla saia armada com crinolina, podendo ser complementada na parte de cima por múltiplas peças, como batas, blusa, tops, casacos ou outros elementos capazes de identificá-las aos personagens representados no enredo. Usa-se, ainda, o recurso de afastar a fantasia do corpo e aumentá-las de tamanho utilizando golas, palas, alegorias de mão, esplendores e "cabeças" e para ampliar sua presença visual em razão da distância plateia e desfile.

\section{Conclusão}

Procuramos mostrar que o desenvolvimento e estabelecimento do tipo "baiana de escola de samba" deram-se a partir da década de 1930, no contexto do carnaval carioca, quando a personagem é construída sob o signo da tradicionalidade a partir de negociações entre a elite intelectual e as camadas populares. A difusão do discurso em torno da baiana e de sua relação com a própria "origem" das escolas de samba seria ele- 
mento importante para a caracterização destes grupos como popular e autêntico. Legitimava-se, desse modo, a ideia de um carnaval puro e ligado às raízes negras. Entretanto, mesmo mantendo a aura da tradição as baianas vêm incorporando continuamente novos significados e funções não só a si mesmas, mas aos próprios desfiles nos quais se representam um momento de forte da visualidade e plasticidade.

Qual uma alegoria em seu sentido clássico e simbólico, sua leitura é indireta e subjetiva e, ainda que em todo o tempo tenha estado relacionada ao enredo, sempre significou mais que o próprio samba-enredo, realizando a operação de uma obra artística a representar diferentes camadas de significados, mediante formas que a tornaram compreensível através do tempo, transitando entre o lúdico e o sagrado, na interface entre a festa carnavalesca e a cultura do samba, num espaço de constante tensão entre tradição e modernidade, fértil em criatividade, experimentação, narrativa, e vigorosa expressão visual.

\section{Referências}

CABRAL, Sérgio e PÉJOUAN, Marie. Carnaval: um outro olhar. Rio de Janeiro: Instituto Herbert Levy, 2004.

FARIA, Guilherme José Motta. O Estado Novo da Portela. Textos Escolhidos de Cultura e Arte Populares, v. 5. Rio de Janeiro, 2007: 125-138.

FERREIRA, Felipe. O marquês e o jegue: estudo da fantasia para escolas de samba. Rio de Janeiro: Altos da Glória, 1999. . O livro de ouro do carnaval brasileiro. Rio de Janeiro: Ediouro, 2004. . Terra de samba e pandeiro: uma história do carnaval, In: KAZ, Leonel e LODDI, Nigge (orgs). Meu carnaval Brasil. Rio de Janeiro: Aprazível Edições, 2009.

LAVER, James. A roupa e a moda: uma história concisa. São Paulo: Companhia das Letras, 1989.

MEIRELLES, Cecília. Batuque, samba e macumba: estudos de gesto e de ritmo 1926-1934. São Paulo: Martins Fontes, 2003.

MOURA, Roberto M. No princípio era a roda: estudo sobre samba, partido-alto e outros pagodes. Rio de Janeiro: Rocco, 2004.

PAVÃO, Fabio. As escolas de samba e suas comunidades. Textos escolhidos de cultura e arte populares, Rio de Janeiro, v.6, n.1, p.183-195, 2009.

SILVA, Marília T. Barboza da e MACIEL, Lygia dos Santos. 
Paulo da Portela; traço de união entre duas culturas. Rio de Janeiro: FUNARTE, Instituto Nacional de Musica, Divisão de Musica Popular, 1989.

THEODORO, Helena. Guerreiras do Samba. Textos escolhidos de cultura e arte populares, v.6, n.1, 2009: 223-235.

TURANO, Gabriel da Costa. A visualidade das escolas de samba na década de 1930: inovação, transformação e reconfiguração. Textos escolhidos de cultura e arte populares, Rio de Janeiro, v.8, n.2, p. 133-142, nov. 2011.

VELLOSO, Monica Pimenta. As tias baianas tomam conta do pedaço: espaço e identidade cultural no Rio de Janeiro. Revista de Estudos Históricos, v. 3, n. 6, FGV, 1990.

Recebido em: 10/12/11

Aceito em: 28/02/2012 


\section{VÂNIA MARIA MOURÃO ARAÚJO \\ vaniamourao@ig.com.br}

Possui mestrado em Artes pela Universidade do Estado do Rio de Janeiro (2011) e especialização em Estudos da Moda e Indumentária (2001). Leciona nas interfaces de pesquisa, criação e desenvolvimento de vestuários de moda e figurinos para TV, teatro e cinema.

\section{LUIZ FELIPE FERREIRA}

felipeferreira@pobox.com

Doutor em Geografia Cultural (PPGG-UFRJ), Mestre em Antropologia da Arte (EBA-UFRJ), Coordenador do Centro de Referência do Carnava e professor do Instututo de Artes da UERJ. Rua Tonelero, 261/201 - Rio de Janeiro - RJ - 22030-001. 